\title{
Neuroendoscopy and the art of painting: reflections from the Dutch Golden Age
}

\author{
Waleed Abdelfattah Azab ${ }^{1}$ (B)
}

Received: 2 April 2019 / Accepted: 14 April 2019 / Published online: 14 May 2019

(C) Springer-Verlag GmbH Germany, part of Springer Nature 2019

\section{A prelude-the paintings of Johannes Vermeer}

The existence of a visual relation between the paintings of Johannes Vermeer of Delft (1632-1675) and endoscopic views of the intracranial cavity was explored and analyzed in a previous publication that I coauthored [1]. The rationale for conducting such an analysis stemmed from the observation that the interior views in Vermeer's paintings evoked an intense impression of similarity to the endoscopic views of the human intracranial cavity (Fig. 1, upper right, upper left).

A closer look at the distinctive characteristics of Vermeer's art discloses why such a sense of similarity is perceived. Vermeer was intensely preoccupied with the behavior of light and other optical effects [2] so that he was entitled "The Master of Light" by some contemporary art scholars [3]. Furthermore, he fastidiously attended to the subtleties of visual expression through geometry, composition, and a precise mastery of the rules of perspective [4]. In their essence, those features are all inherent to the nature of neuroendoscopic views being conveyed to the observer by an optical device.

\section{Optical devices and optical realism in the Dutch Golden Age painting}

Many scholars provided compelling evidence that Vermeer most likely used a camera obscura to produce his paintings $[5,6]$, providing a physical explanation for

Waleed Abdelfattah Azab waleedazab@hotmail.com

1 Department of Neurosurgery, Ibn Sina Hospital, P.O Box: 25427, 13115 Safat, Kuwait such eminent optical realism seen in his paintings (Fig. 1, lower right, lower left). Optical realism seems to be a key factor contributing to the perceived visual similarity between Vermeer's paintings and endoscopic views. Apart from Vermeer's paintings, many works of other Dutch Golden Age masters like Rembrandt van Rijn (1606-1669), Johannes Cornelisz Verspronck (1600-1662), Gerrit Duo (1613-1675), and Gerard Ter Borch (1617-1681) share visual atmospheres and optical features with endoscopic views of the intracranial cavity (Fig. 2 and Cover).

In the Hockney-Falco thesis, the artist David Hockney and the physicist Charles Falco provide evidence that the notable realism and accuracy of the European Renaissance paintings after c.1430 resulted mainly from using optical instruments such as curved mirrors, camera obscura, and camera lucida. Optical instruments were used to project images of objects illuminated by sunlight onto boards or canvas. Subsequently, some portions of the projected image are traced, altered, or completely ignored according to the painter's artistic vision [6,7]. Historical and artistic evidence made it currently wellknown that the French painter Jean-Auguste-Dominique Ingres $(1780-1867)$ used a camera lucida to produce his portraits [6,8], and that Gerrit Dou (1613-1675), one of Rembrandt's students, employed grids, lenses, and mirrors to make his finely executed paintings $[6,9]$.

\section{Rembrandt's portraits and neuroendoscopy}

The art of Rembrandt deserves a deeper look when the visual relationship between painting and neuroendoscopy is explored. In my opinion, a remarkable optical relation between Rembrandt's portraits and neuroendoscopic views is truly present. In a recent study conducted by the researchers F. O'Neill and S. Corner and published in the Journal of Optics in 2016, the authors provided 

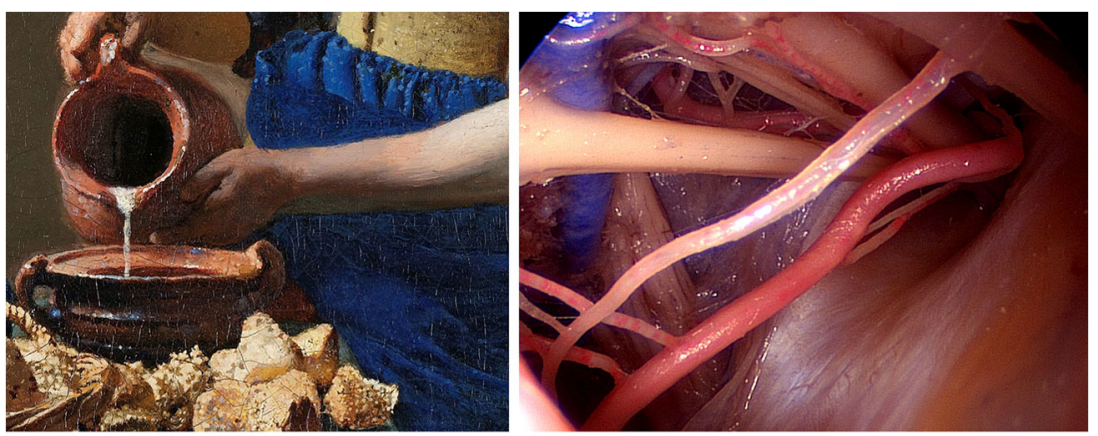

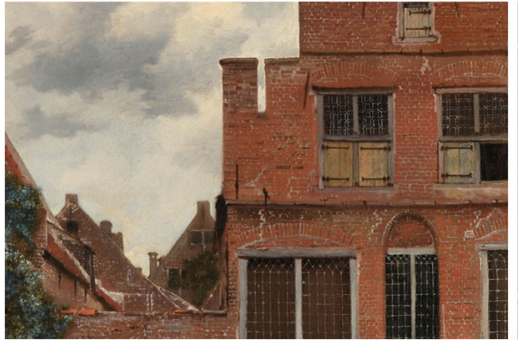

Fig. 1 The sense of similarity between Vermeer's paintings and endoscopic views of the human intracranial cavity (upper panel). Note the similarity of the woman's lower forearm in this detail from Vermeer's The Milkmaid (left) to the cranial nerve in the endoscopic view (right), and the convergence of both forearms into the milk vessel in a visually similar fashion to both cranial nerves converging into the jugular foramen in the endoscopic view. The optical realism in Vermeer's painting (lower

further evidence that Rembrandt used lens and mirror technology to make his famous self-portraits [9]. Human figures in Rembrandt's portraits are located within the center of the composition and exposed to directional light that unveils their details. Such a pattern of composition is conceptually identical to neuroendoscopy during which the endoscope is navigated towards a structure of interest so that it is put in the center of view, closely inspected and subsequently manipulated.

To gain a further insight into this impression, I conducted a simple experiment in which contemporary female pearl accessories similar to those worn by the lady in Rembrandt's Portrait of a Woman, Possibly Maria Trip,1639, were viewed using a 4-mm rigid lens-scope connected to a full HD endoscopic camera. Comparing the endoscopic view to the detail in Rembrandt's painting conveyed an intense feeling of visual similarity (Fig. 3).

\section{Light effects and manipulation}

It seems that the use of optical instruments and light effects are the most critical factors joining these seemingly different worlds. Light was Rembrandt's holy grail. $\mathrm{X}$-ray examinations of his works revealed that he worked from back to front, starting in the shadows and then painting his luminous figures at the end [10]. More specifically, one of the well-known features of Rembrandt's

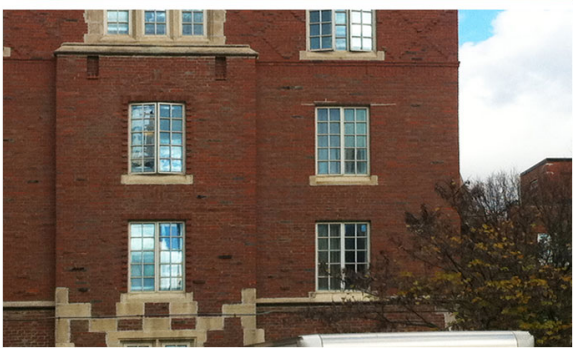

panel) is exemplified by comparing the detail from Vermeer's The Little Street (left) to a contemporary building photographed by the author (right). (Photo credit - upper panel: modified from Azab W, Prevedello D, Carrau R (2014), Surgical Neurology International [1], Copyright: (C) 2014 Azab WA. Upper left: Detail from Johannes Vermeer, The Milkmaid. c. 1660, Rijksmuseum, Amsterdam. Lower left: Detail from Johannes Vermeer, The Little Street. c. 1658, Rijksmuseum, Amsterdam)

portraiture work was the outstanding use of Chiaroscuro - an oil painting technique in which strong tonal contrast between light and dark are used to model three-dimensional forms [5]. This phenomenon is frequently observed during intracranial endoscopy, especially in endoscopic skull-base procedures when structures are seen from different angles in close-up views.

Vermeer's light effects, on the other hand, were generally characterized by an exquisite luminous unity which is also an important feature of the neuroendoscopic visual output. His coherent three-dimensional spaces were filled with natural light [11] that was channeled, diverted, and reflected with total logic from one surface to another, thus infusing space, color, and form with such a glorious luminous unity [12].

\section{The esthetic aspect of neuroendoscopy and its value}

The proposed similarity between neuroendoscopy and the art of painting is not intended to imply an exact match between the two visual worlds. What is being elaborated upon here is rather an attempt to shed light on an esthetic aspect of the endoscopically conveyed scenery of the human intracranial cavity. The beauty that we experience during neuroendoscopic procedures derives, in the first place, from the original beauty of human anatomy. That the endoscope is capable of 


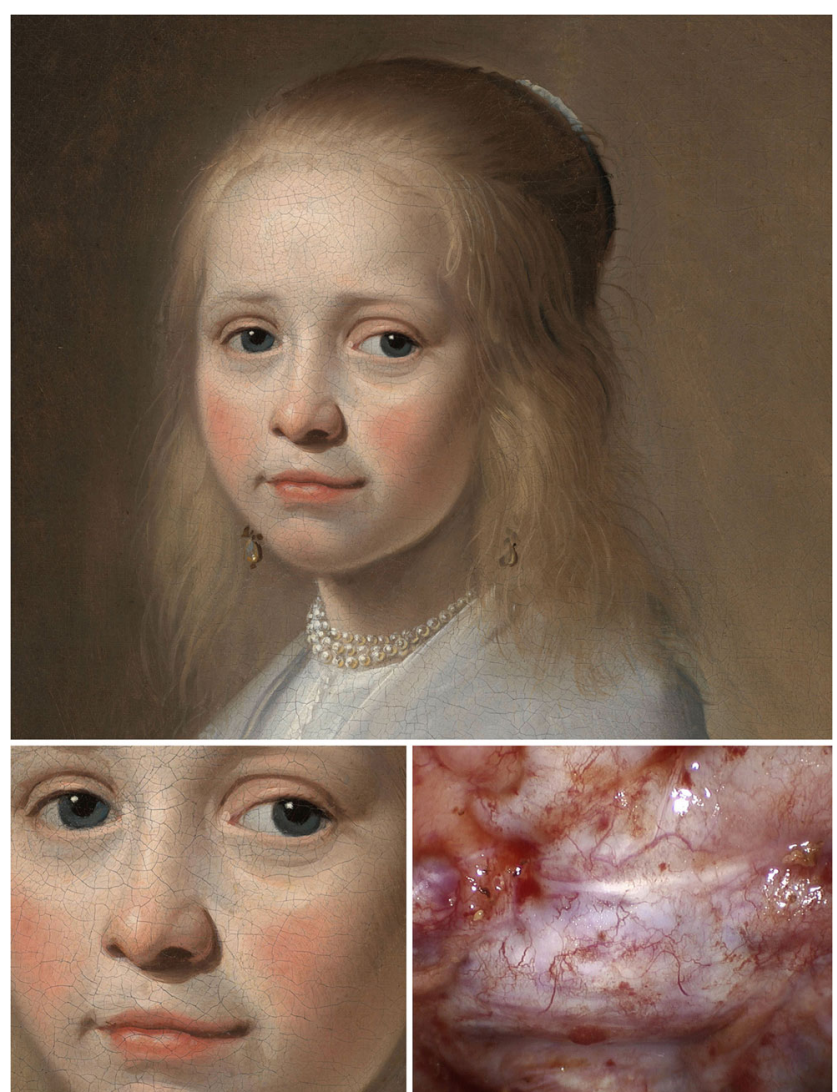

Fig. 2 and Cover The shared visual atmospheres and optical features between a detail from Johannes Conelisz Verspronk's Portrait of a Girl Dressed in Blue (lower left) and an endoscopic view of the anterior skull base (lower right). Note the similarity between the lower lip and its curvature into the chin in the painting and the curvature of the sellar dura into the dura of the inferiorly located clival recess in the endoscopic view. Additional features of similarity include the blushed right cheek in the painting and the right cavernous sinus in the endoscopic view, and the faint bright line at the upper border of the girl's left cheek and the line demarcating the diaphragma sellae. (Photo credit-Portrait of a Girl Dressed in Blue, Johannes Cornelisz. Verspronck, 1641, Rijksmuseum, Amsterdam)

displaying this beauty before the eyes of the beholder is a feature of neuroendoscopy that in itself deserves our praise.

Ever since the humanity existed, it was realized that experiencing beauty has a positive impact on the psychology of human beings and their performance at all levels. Cognitive studies found that esthetic experience emerges from bodily and emotional engagement with works of art via complementary processes that modulate the overall affect and attitude [13]. Moreover, studies in the field of neuroaesthetics used functional MRI to demonstrate that experiencing beauty induces specific patterns of cerebral activity, like the activation of field A1 of the medial orbitofrontal cortex by beautiful visual or auditory stimuli [14] and the activation of caudate nucleus during experience of visual beauty $[14,15]$ in a fashion similar to that which occurs during romantic love $[16,17]$.

From this perspective, an endoscopic procedure can be transformed into an esthetic experience that brings about a

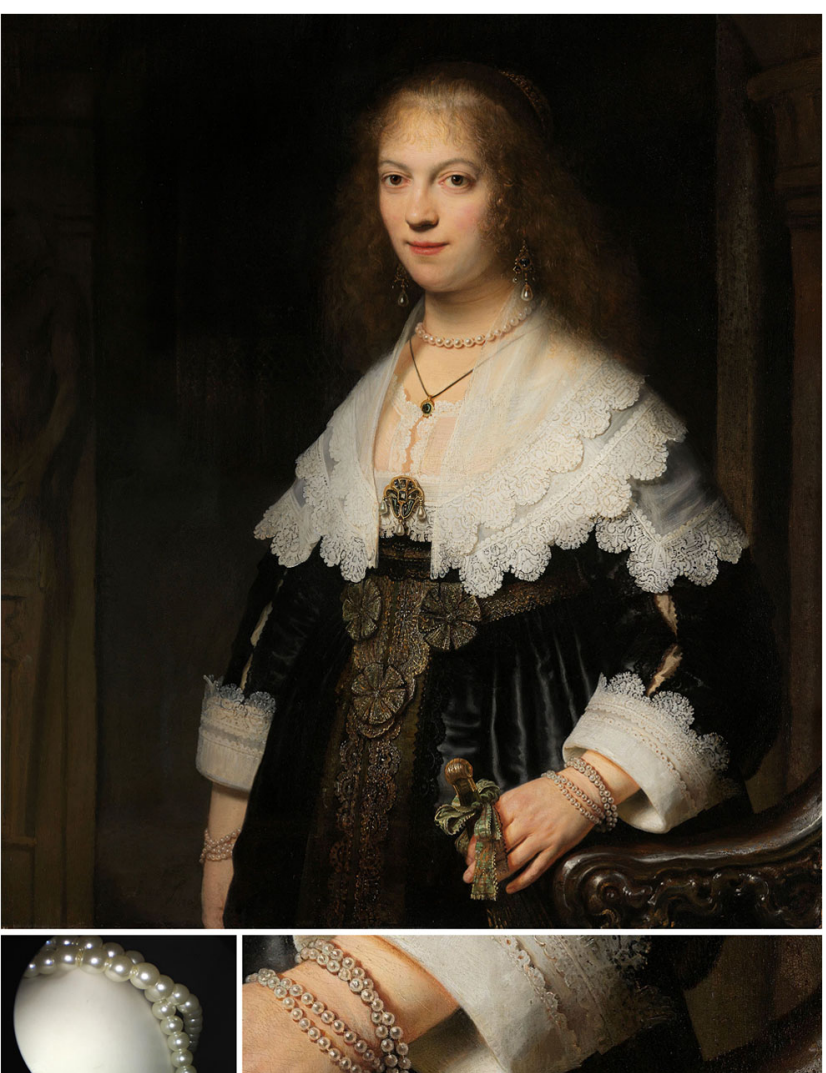

Fig. 3 Rembrandt's portraits and neuroendoscopy. Portrait of a Woman, Possibly Maria Trip, Rembrandt van Rijn, 1639, Rijksmuseum, Amsterdam (upper panel). Note the very close similarity between the endoscopically viewed contemporary female pearl accessories (lower left) and the detail from Rembrandt's painting (lower right)

state of pleasure boosting the performance of the operating neurosurgeon. It is my belief that our perception of the endoscopic image acquires a well-deserved philosophical dimension when that image is seen as a piece of art in addition to its purely anatomical identity.

\section{Compliance with ethical standards}

Conflict of interest The corresponding author states that there is no conflict of interest.

\section{References}

1. Azab WA, Prevedello DM, Carrau RL (2014) Johannes Vermeer of Delft 1632-1675 and vision in neuroendoscopy. Surg Neurol Int 5: 123. https://doi.org/10.4103/2152-7806.138206

2. Liedtke W (2003) Johannes Vermeer (1632-1675). In Heilbrunn timeline of art history. The Metropolitan Museum of Art. http:// www.metmuseum.org/toah/hd/verm/hd verm.htm. Accessed 19 Feb 2019

3. Miranda CM (2009) Johannes Vermeer and Anthon van Leeuwenhoek. Delft Art and Science together during the Golden Dutch Century. Rev Med Chil 137:567-574 
4. Stone HA (2006) Preface. In: Stone HA (ed) Tables of knowledge: Descartes in Vermeer's studio, 1st edn. Cornell University Press, New York, pp 11-36

5. Steadman P (2001) Vermeer's camera: uncovering the truth behind the masterpieces. Oxford University Press, Oxford

6. Hockney D (2001) Secret knowledge: rediscovering the lost techniques of the old masters. Viking Studio, New York

7. Falco CM (2018) Art optics. https://wp.optics.arizona.edu/falco/artoptics/ Accessed 14 March, 2019

8. Lüthy C (2005) Hockney's secret knowledge, Vanvitelli's camera obscura. http://www.jstor.org/stable/4130315. Accessed 12 Dec, 2018

9. O’Neill F, Corner SP (2016) Rembrandt's self-portraits. J Opt 18: 080401. https://doi.org/10.1088/2040-8978/18/8/080401

10. Watson B (2016) The secret of Rembrandt. http:/light-radiant.com/ 806-2/ Accessed 8 Mar 2019

11. Janson J (2001) A girl reading a letter by an open window. In: Essential Vermeer. http://www.essentialvermeer.com/catalogue/ girl reading a letter by an open window.html. Accessed 9 Mar 2019
12. von Sonnenburg H (1973) Technical comments. The Metropolitan Museum of Art Bulletin. http://www.metmuseum.org/pubs/ bulletins/1/pdf/3258581.pdf.bannered.pdf. Accessed 15 Mar 2019

13. Brinck I (2018) Empathy, engagement, entrainment: the interaction dynamics of aesthetic experience. Cogn Process 19(2):201-213. https://doi.org/10.1007/s10339-017-0805-x

14. Ishizu T, Zeki S (2011) Toward a brain-based theory of beauty. PLoS One 6(7):e21852. https://doi.org/10.1371/journal.pone. 0021852

15. Vartanian O, Goel V (2004) Neuroanatomical correlates of aesthetic preference for paintings. Neuroreport 15:893-897

16. Bartels A, Zeki S (2000) The neural basis of romantic love. Neuroreport 11:3829-3834

17. Aron A, Fisher H, Mashek DJ, Strong G, Li H, Brown LL (2005) Reward, motivation, and emotion systems associated with earlystage intense romantic love. J Neurophysiol 94:327-337

Publisher's note Springer Nature remains neutral with regard to jurisdictional claims in published maps and institutional affiliations. 